2006-502: AN ASSIGNMENT FOR AWARENESS OF SOME ENVIRONMENTAL ISSUES RELATED TO THERMODYNAMICS

Nihad Dukhan, University of Detroit Mercy 


\title{
An Assignment for Awareness of Some Environmental Issues Related to Thermodynamics
}

\begin{abstract}
The new ABET criteria outcome $(\mathrm{h})$ is the broad education necessary to understand the impact of engineering solutions in an environmental and societal context. This was partially addressed by selecting an assignment for a class of seven students taking the first course of thermodynamics at the mechanical engineering department of the University of Detroit Mercy. The assignment consisted of identifying one of the negative impacts of energy conversion on the environment, describing it, its cause, the pollutants associated with it, its effect on the environment and any governmental regulations that deal with it. The students selected acid rain, greenhouse effect and smog formation. They worked in three groups. The assignment proved to be beneficial in many ways. It put one of the topics of thermodynamics in perspective. The assignment also partially fulfilled one of the targeted outcomes for accreditation, as mentioned above. The benefits of the assignment on the students' understanding of some of the environmental issues were assessed by carefully analyzing their reports and by using a survey that they had to complete. Both methods showed that the students enjoyed and learned a great deal about the topic they had to write about. When asked if the assignment would resonate with them after graduating, they all said 'yes', and thus they would take the environmental effects as a factor when making engineering decision.
\end{abstract}

\section{Introduction}

The vast and rapid technological change, growing population, the looming energy shortages, and the increasing environmental issues has called for changes in engineering curricula to prepare engineering students for the future.

Under Criterion 3 titled Program Outcomes and Assessment, item (c), the Accreditation Board of Engineering and Technology (ABET) states that all engineering programs must demonstrate that their students have "an ability to design a system, component, or process to meet desired needs within realistic constraints such as economic, environmental, social, political, ethical, health and safety, manufacturability, and sustainability." Under item (h), it says that the students must have "the broad education necessary to understand the impact of engineering solutions in a global, economic, environmental, and societal context." [1].

The National Academy of Engineering in their report titled The Engineer of 2020: Visions of Engineering in the New Century says: "The world faces significant environmental challenges in the future. At the same time there is a great opportunity for engineering to serve as a force to help society solve the problems associated with these challenges. This requires a holistic understanding of economic growth and development in terms of the principles of sustainability. The present generation has the obligation to leave a legacy to those who follow so they can have the opportunity to appreciate the unrestrained beauty of nature, the full diversity of the world's flora and fauna, and ancient and modern cultures and their artifacts. It is our aspiration that engineers will 
continue to be leaders in the movement toward use of wise, informed, and economical sustainable development. This should begin in our educational institutions and be founded in the basic tenets of the engineering profession and its actions [2]."

Reference [3] includes the students' knowing of the engineering practice within a global, environmental and societal context as one of the 'awareness skills'. It also indicates that mastering such skills will be a major determinant of the future competitiveness of engineering graduates.

Agenda 21, a global action plan for delivering sustainable development accepted at the Earth Summit in Rio de Janeiro in 1992, stated that "education is critical for promoting sustainable development and improving the capacity of the people to address sustainable development issues [4]'. The international survey of Ref. [4] found out that engineering students had weak knowledge of many of the environmental issues such as: acid rain, air pollution, deforestation, global warming, ozone depletions and water pollution. The knowledge of environmental legislation, policy and standards was exceptionally lacking.

This paper addresses some partial education of some mechanical engineering students at the University of Detroit Mercy in environmental issues. This was done through a small project assigned to students in their first thermodynamics course. This paper does not claim that it covers all aspects of the engineering education required with regards to the environment, but can serve as an example that could be repeated in many engineering courses as appropriate.

The assignment was given to a small class of seven undergraduate students. The class consisted of five males and two females. They were all seniors in the mechanical engineering program at the University of Detroit Mercy. The students were divided into three teams: two two-student teams and one three-student team.

\section{The Assignment}

The project was a simple assignment asking the students to write a report, limited to two pages, about the general theme of energy and the environment, specifically on one of the following three important contemporary topics: ozone and smog, acid rain and the greenhouse effect.

For a given topic, the students were asked do describe in writing the following:

- the environmental problem and its cause,

- the pollutants involved and their adverse effects,

- any regulations that are concerned with the problem, and their comments on the regulations, and

- suggested solutions.

The assignment was based on a section in the course text book [5]. The topic of energy and the environment was put in the context of some energy conversion processes 
and the way their efficiencies are computed. The text book provided the students with a basis and a starting point. It also introduced the topics and the terminology associated with them. As an incentive, the students were given a few percentage points towards their final grade in the course. The best students' paper is presented in the Appendix.

\section{Students' Survey and Educational Results}

After the assignment was completed, a short survey of seven questions was administered to the students to assess the learning experience. The survey asked the following questions:

1. What did you work on?

2. Did you enjoy the assignment?

3. What references did you use?

4. Do you feel you learned a lot about the topic you had to write about?

5. Do you think you will use what you learned in making engineering decisions in the future? How?

6. Do you think the assignment will make you likely to think about other environmental issues? How?

7. Any comments?

According to Ref. [3], the students are forced to think about their learning in profound ways, when they are actively involved in their own assessment.

All the students indicated that the assignment was both enjoyable and interesting, and that it made them learn about the perspective environmental topic. A couple of students stated that they learned things that they had not previously thought about, such as the existence and the difference between wet and dry deposition of acid rain.

Besides the text book, the students stated that they made extensive use of the Internet, including government, magazine and newspaper web sites. One student wrote that the web has a lot of information that did not provide an in-depth treatment of the topics, and that it was difficult to sieve through the large set of Internet articles on a particular topic.

Four students said that they would use the knowledge they acquired in making future engineering decisions, while one said it was possible that he would use it. One of the remaining students said that he would be working with CAD, so that he would not be in a position where the environmental issues described above would be relevant. The last student said that in real life, time was at a premium and that an engineer might not have the full freedom when it comes to making decisions.

All the students agreed that the assignment brought attention to the specific environmental topics discussed and that it would make the students think about other environmental issues in the future. 


\section{Conclusion}

An assignment in a first course in engineering thermodynamics that targeted the students' awareness of some environmental issues was described. The effect of the assignment on the students was assessed by a survey. The results showed that the students learned a great deal about the environmental issues they had to write about. The students indicated that the assignment made them more aware of the environmental issues and that they would consider them in making their future engineering decisions.

\section{Bibliography}

[1] The Accreditation Board for Engineering and Technology (ABET): www.abet.org.

[2] The National Academy of Engineering, "The Engineer of 2020: Visions of Engineering in the New Century," National Academic P, Washington D.C., 2004.

[3] Shuman, L. J., Besterfield-Sacre, M. and McGoury, J., "The ABET "Professional Skills"- Can They Be Taught? Can They Be Assessed?," Journal of Engineering Education, Vol. 94, No. 1, January 2005, pp. 41-55.

[4] Azapagic, A., Perdan, S. and Shallcross, D., "How Much Do Engineering Students Know about Sustainable Development? The Finding of an International Survey and Possible Implications for the Engineering Curriculum," European Journal of Engineering Education, Vol. 30, Issue 1, March 2005, pp. $1-19$.

[5] Cengel, Y. A. and Boles, M. A., "Thermodynamics: An Engineering Approach," 5 ${ }^{\text {th }}$ Ed., McRaw-Hill, NY, 2006, pp. 86-91. 


\section{Appendix: Sample Paper}

\section{The Effect of Energy Conversion on the Levels of Ozone and Smog in the Environment}

The conversion of fossil fuels into usable energy sources plays a vital role in the lives of nearly everyone on the planet. Yet these conversion processes are major contributors to the decline of global air quality, and to the pollution of the environment as a whole, which leads directly to human health problems and threats to wildlife and vegetation. The burning of gasoline in motor vehicles is the primary source for air pollution, which shows up in the environment as ground-level ozone and smog.

Smog is most commonly found in large urban areas. It appears as a dark yellow or brown haze, which floats over these cities on hot summer days. Smog is made up mostly of ground level ozone $\left(\mathrm{O}_{3}\right)$, which is produced when hydrocarbons and nitrogen oxides react in the presence of sunlight. Ground level ozone should not be confused with the good ozone, which is layered in the earth's stratosphere, and protects the earth from harmful UV radiation.

Smog also contains other chemicals such as particulate matter and Volatile Organic Compounds (VOCs) such as benzene, butane and other hydrocarbons. The burning of fuel by internal combustion engines is very inefficient. Only about $30 \%$ of the fuel is converted into the energy that propels the vehicle. The rest is lost to the environment in the form of heat, hydrocarbons (HC), carbon monoxide $(\mathrm{CO})$, and nitrogen oxides (NOx). The byproducts of the internal combustion engine, coupled with the catalytic effects of sunlight on these byproducts, produce all of the ingredients of smog.

The smog causes many adverse health effects including respiratory problems and cancer. Ozone irritates the eyes and hardens the soft spongy tissue in the lungs. This reduces the lungs' capacity to absorb oxygen and remove carbon dioxide from the bloodstream. Ozone also harms vegetation by damaging leaf tissues. Carbon monoxide affects the ability of the body to absorb oxygen by binding to the red blood cells, which would normally carry oxygen. At low levels $\mathrm{CO}$ reduces the oxygen supply to the brain, other organs and the muscles. A young child and an unborn fetus are particularly susceptible to these effects because of their tremendous growth potential. At high levels, $\mathrm{CO}$ is fatal to animals and humans.

The increase in environmental pollution has forced the governments around the world to enact legislation that limits the allowable emissions of industries and vehicles. In the United States, the Clean Air Acts of 1970 and 1990 set limits on pollutants emitted by large plants and vehicles. Some states in the U.S. have gone a step further and required that motor vehicle companies limit emissions even further and sell a certain number of zero-emission vehicles (ZEV) in their state. If the companies don't achieve the required $\mathrm{ZEV}$ credits they will be unable to sell their product in these states. 
The Clean Air Acts have made some progress in limiting pollution. The laws have been written, but enforcement is long overdue. In the 1970's, when the first Clean Air Act came into affect, large power stations were given dispensation to forestall adherence to the new emission limits until it was time for major overhauls. Many power stations have taken advantage of this dispensation, and twenty-five years later, have yet to comply. It has been documented by environmental groups that the power stations have had major overhauls without being upgraded and these overhauls have been disguised as maintenance. It has been fifteen years since the last act was written to further limit harmful emissions and the time has come to enforce them.

Motor vehicle companies have invented technologies that have lowered tailpipe emissions, such as catalytic converters, and electronic engine management, which closely coordinates many engine parameters through continuous process control to ensure economical and ecological engine performance. These improvements have reduced the HC emissions in cars from 8 grams per mile (gpm) in 1970 to 0.4 gpm in1980, and down to about $0.1 \mathrm{gpm}$ in 1999. Ford Motor Company and three other Japanese auto makers are now selling full Hybrid vehicles to the public. These vehicle are particularly suited to urban stop-start driving were smog is a major problem. Full hybrid vehicles use a strategy of shutting the engine down as the vehicle comes to a stop, which happens frequently in urban driving. Hybrids also have regenerative braking, which allows the vehicle to recapture the energy normally lost as heat and use it to charge the battery. Major breakthroughs have been made in hydrogen fuel cell technology in the recent years. A fuel cell has zero tail pipe emission. These vehicles are currently very expensive to produce. Auto companies need more time to solve some major problems with this technology, such as making some of the parts affordable for mass production (producing hydrogen with smaller amounts of energy). Currently it takes large amounts of energy to extract hydrogen. This required energy, in the form of electricity, comes from coal- or gas-burning power stations, whose emissions effectively counteract the effect of a zero emission fuel cell.

There can be no doubt that the conversion of fossil fuels into usable energy via the internal combustion engine causes a significant negative impact on the environment in the form of tailpipe emissions and smog. But with the correct technologies incorporated into our vehicles, we can substantially reduce these emissions and significantly lower the global problem of urban smog. Auto companies must continue research into new, cleaner burning fuels and alternate energy sources, as well as new technologies that improve the efficiencies of the internal combustion engine, to ensure the earth's sustainability. 